\title{
ASSESSMENT OF DEVELOPMENT FACTORS OF INDUSTRIALIZED RURAL MUNICIPALITIES IN STARA ZAGORA DISTRICT
}

\author{
K. Toneva* \\ Faculty of Economics, Trakia University, Stara Zagora, Bulgaria
}

\begin{abstract}
BSTRACT
Rural areas are part of the territory of each country and its identity. Much of the territory of the Member States of the EU applies to rural areas, where a lot of European citizens live.

Regional development is closely linked to the rural development. It provides conditions for enhancing the quality of life, leading to a reduction of regional disparities.

Rural areas in Bulgaria are distinguished by their specificity and opportunities for development.

The aim of the report is to assess the factors for the development of industrialized rural municipalities in the region of Stara Zagora and to make recommendations to state and local authorities towards the successful implementation of the strategic objectives for the period 2014-2020.
\end{abstract}

Key words: regional development, rural areas, industrialized rural municipalities, Stara Zagora district.

\section{INTRODUCTION}

Rural areas constitute a part of the territory of every country and contribute to its identity. A considerable part of the territory of all member-states of the European Union (EU) is included in the rural areas and it is populated with a great number of European citizens.

According to the European commission more than $91 \%$ of the territory of EU consists of "rural areas" inhabited by more than $56 \%$ of the population of all 27 member states of the Union (1)

Many of the rural areas face considerable challenges. Most of their enterprises (mostly forestry and agriculture) still need to become competitive. The average income per capita in the rural areas is lower than the cities and the service sector is far less developed. In addition, protection of environment always requires bigger financial costs. Agriculture and forestry remain crucial for land cultivation and natural resource management in the EU rural areas and a starting point for the diversification of the economy in the rural communities. That is why strengthening of the EU policy for rural development has become main priority of EU.

\footnotetext{
*Correspondence to: Krasimira Toneva, Faculty of Economics, Trakia University, Stara Zagora, Bulgaria., tel.: +359898218630, e-mail: k_toneva@abv.bg, Stara Zagora 6000,Student Campus.
}

On the other hand, Europe's rural areas can offer so much. They provide extremely important raw materials. Their contribution into providing beautiful spots for rest and recreation - as long as we take good care of them - is unquestionable. Many people are attracted by the idea of living and/or working in them if they have an access to required services and infrastructure.

According to a Report from the International Fund for Agricultural Development (IFAD) (2) the lack of homogeneity of rural areas throughout all of EU and the member - states represent a serious problem when developing programs and vision statement for the European and National Policies for Rural Areas. This diversity and "mixture" of economic, social and cultural differences should be taken into account in order to ensure individual approach when developing solutions.

In compliance with Europe 2020 Program and the targets of the Common Agricultural Policy (CAP) there can be identified three long-term strategic goals for the EU policy for rural areas' development for the period 2014-2020:

- Promoting agricultural competitiveness;

- Ensuring sustainable development of natural resources and climate - related activities; and

- Achieving balanced territorial spread of businesses and communities in rural areas, 
including creating and maintaining of employment (3).

The rural areas in Bulgaria should follow the developmental guidelines of EU, i.e. it should follow the goals accepted in the EU framework but at the same time it should not overlook the regional specifics. The rural economy should include all components, i.e. not only agriculture but also local businesses, services, communal life, cultural and natural heritage and other fields.

The rural areas of EU are diverse in terms of physical, socio-economic, environmental and institutional factors. This diversity is one of the biggest resources in Europe but also a cause of difficulties for few member-states when it comes to correct definition of a rural area. This definition is particularly important for the development of a proper EU policy for rural development and ensuring its topping up with other EU funds, related to the development of rural areas, which is essential for rural areas with special requirements.

\section{RURAL AREAS AND THEIR FACTORS OF DEVELOPMENT}

In the European legislature and jurisprudence so far there is no uniform definition for what is a rural area in EU. Every member-state has its own local definition for these regions. The definition of the Organization for Economic Co-operation and Development (OECD) has been used for the sake of benchmarking in EU and for outlining the strategic guidelines of EU and according to it a rural area is any territory on municipal or residential level that has a population density below 150 people on a square kilometer.

Also as per OECD predominantly rural are named those regions that have more then $50 \%$ of its population living in village communities. Village communities are municipalities with a population density below 150 residents on a square meter.

Taking into account the diversity of EU rural areas, it is important for every member state and every region to use the correct definition for a rural area and to apply the relevant typology according to the context.

Contextually speaking there are three main elements that might be used for the definition of rural areas' typology:

- level of unfavorable ambient conditions;

- sensitivity with regard to environment;

- disadvantageous social and economic situation.
The correct measurement of every element might lead to creation of individual typologies suitable for a given member - state or region. Every main element consists of individual factors and every factor could be measured with a specific set of factors (4).

Bulgaria is not applying OECD's definition because according to it $98,8 \%$ of the country's territory and $84,3 \%$ of the population should qualify as Predominantly Rural (PR) or Intermediately Rural (IR) regions.

On the basis of these three definitions for regional identification and the available information for the population and territory of each community, for Stara Zagora District this relation is as follows:

- As per OECD identification, 10 of all 11 municipalities of Stara Zagora District fall into the rural category;

- As per Eurostat identification, 9 from the municipalities fall into the group of poorly populated territories and 2 - in the intermediate group;

- As per the National Definition, two of the municipalities are identified as cities (Stara Zagora and Kazanlak), and the remaining nine (Bratya Daskalovi, Gurkovo, Galabovo, Maglizh, Nikolaevo, Opan, Pavel Banya, Radnevo and Chirpan ) - as rural.

When looking into the typology of the rural areas in Bulgaria, there is a big difference between the municipalities on all factors, which are used to characterize them such as territorial coverage, number of population and density (5).

Natural, economic and social factors form the basis for development of every region.

In the last 25 years there is a permanent tendency for the negative processes in the Bulgarian rural areas - depopulation, fading away of economic activities, dipole type of agriculture, deterioration in the quality of life.

The municipalities of Galabovo and Radnevo are situated in a region rich in low-calorific lignite coal and their territory is part of the East Maritsa Coal Basin. Coal mining and electricity production are the defining sectors of the local economy. They also predetermine the origination of a number of additional businesses and services.

Galabovo and Radnevo occupy one of the top places among all municipalities in terms of social and economic development measured by the gross domestic product per capita of population. 
According to the official demographic data (as of 31.12.2014) the population of both municipalities numbers 31767 people, which is 9,7\% of the population of Stara Zagora district and approximately $33,0 \%$ of the population of its rural municipalities.

\section{PURPOSE, ACTIONS AND}

\section{METHODOLOGY OF THE RESEARCH}

The purpose of this research is to assess some of the development factors of industrialized rural communities on the territory of Stara Zagora District.

The actions for achievement of this purpose include: 1) identification of industrialized rural communities in the Stara Zagora district for the sake of this research; 2) preparation of a questionnaire and a field survey; 3 ) processing and analysis of questionnaire data.

The regional cross-cut of data received for the factor "manufactured products" and net sales income from business activities for 2013(6) identifies the municipalities of Galabovo and Radnevo as the object of this research.

The subject of this research are the questions in the questionnaire poll about the specific characteristics of the villages and rural areas, which help attract people and the degree of importance of individual factors for the future development of villages and rural areas in Bulgaria.
The conducted questionnaire poll in the municipalities of Galabovo and Radnevo is representative. It includes all 33 populated areas (11 in the municipality of Galabovo and 22 in the municipality of Radnevo), which form both municipalities. The participants in the poll are chosen randomly and range from 18 to 65 years of age.

The questions related to rural area specifics, which help attract people were assessed on a rank scale used to receive a weighted average rank. The possible number of ranks of importance is 7 , allowing ranking from 1 to 7 , whereby 1 - st rank designates the biggest importance and 7-th - lowest importance.

The assessment of the factors for future development of rural areas is done via 5-rank scale whereas first rank means „no contribution“, second - ,insignificant“, third „partial“, forth - ,significant" and fifth "decisive role“.

\section{RESULTS, CONCLUSIONS}

Half of the participants in the survey point out that top importance is given to the factor „healthier and environmentally - friendly lifestyle ". $16 \%$ rank it second. It is worth noting that the same percentage of participants place this factor on the last place (Figure 1). The weighted average rank for this factor is 2 , 7.

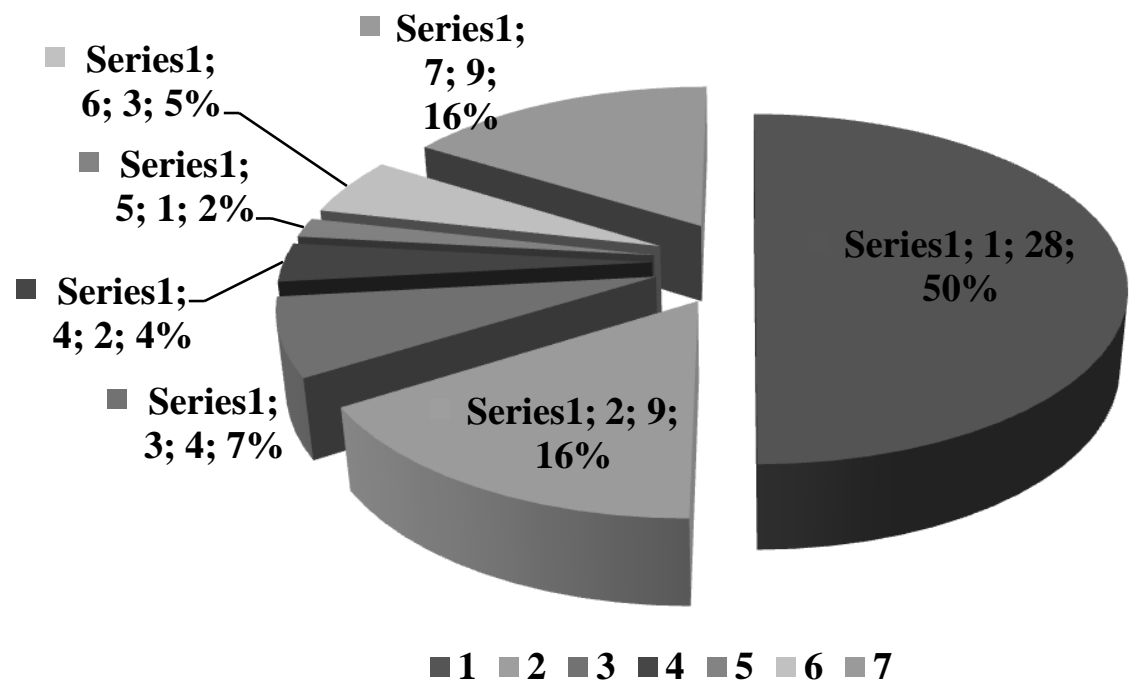

Figure 1. Ranking of the factor „healthier and environmentally friendly lifestyle“

For $56 \%$ of interviewed ,more tranquility and lack of every day stress "is the most important factor. $13 \%$ rank it second. Idenitcal is the relative share of interviewed that have placed this factor on the last place of importance (Figure 2).

The weighted average rank of this factor is 2 , 6. 


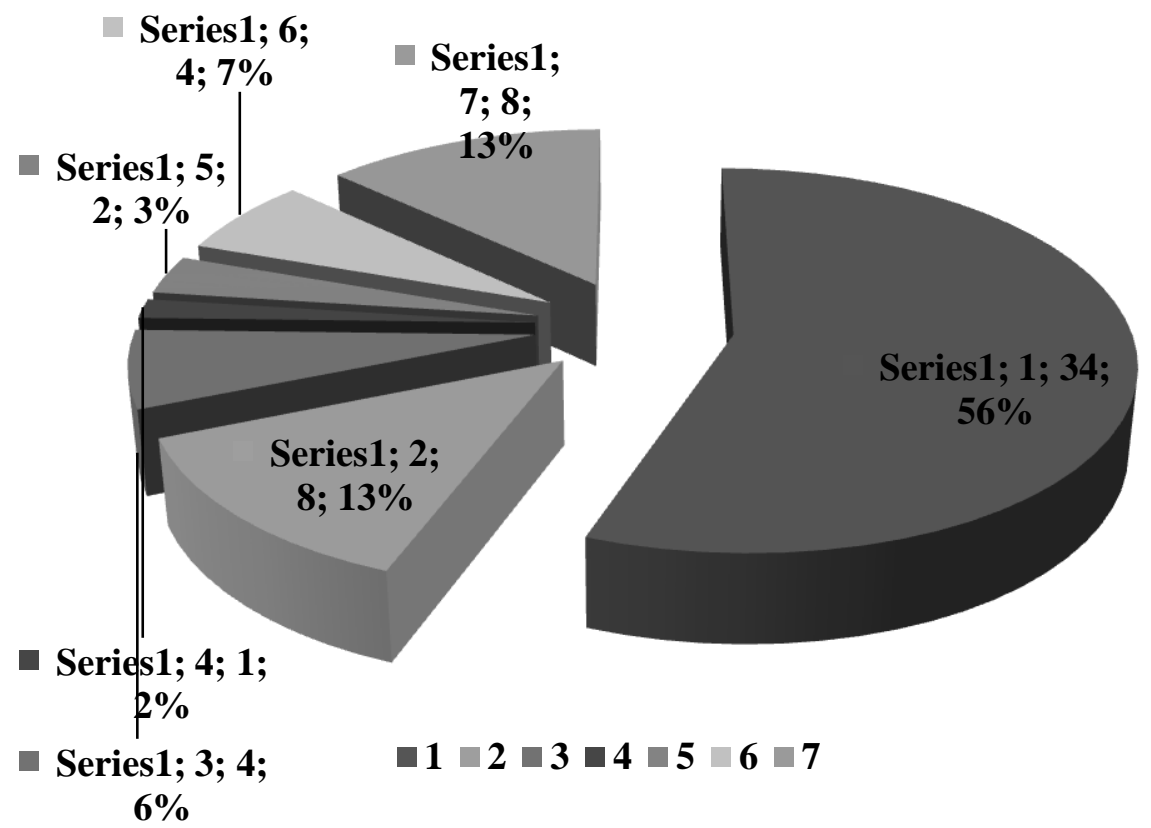

Figure 2. Ranking the importance of the factor „,more tranquility and lack of everyday stress“

$23 \%$ of the interviewed, place the factor „,bigger detachment and independence“ on the first place in importance. Its worth noting, that the rankings for first and second place are relatively similar (23\% and $20 \%)$, as well as fifth, fourth and third - respectively 16, 14 and
$13 \%$. For $9 \%$ of the participants in the poll, this factor is on the last place of importance and 5\% place it before last (Figure 3).

The weighted adverage rank of this factor is 3,9 .

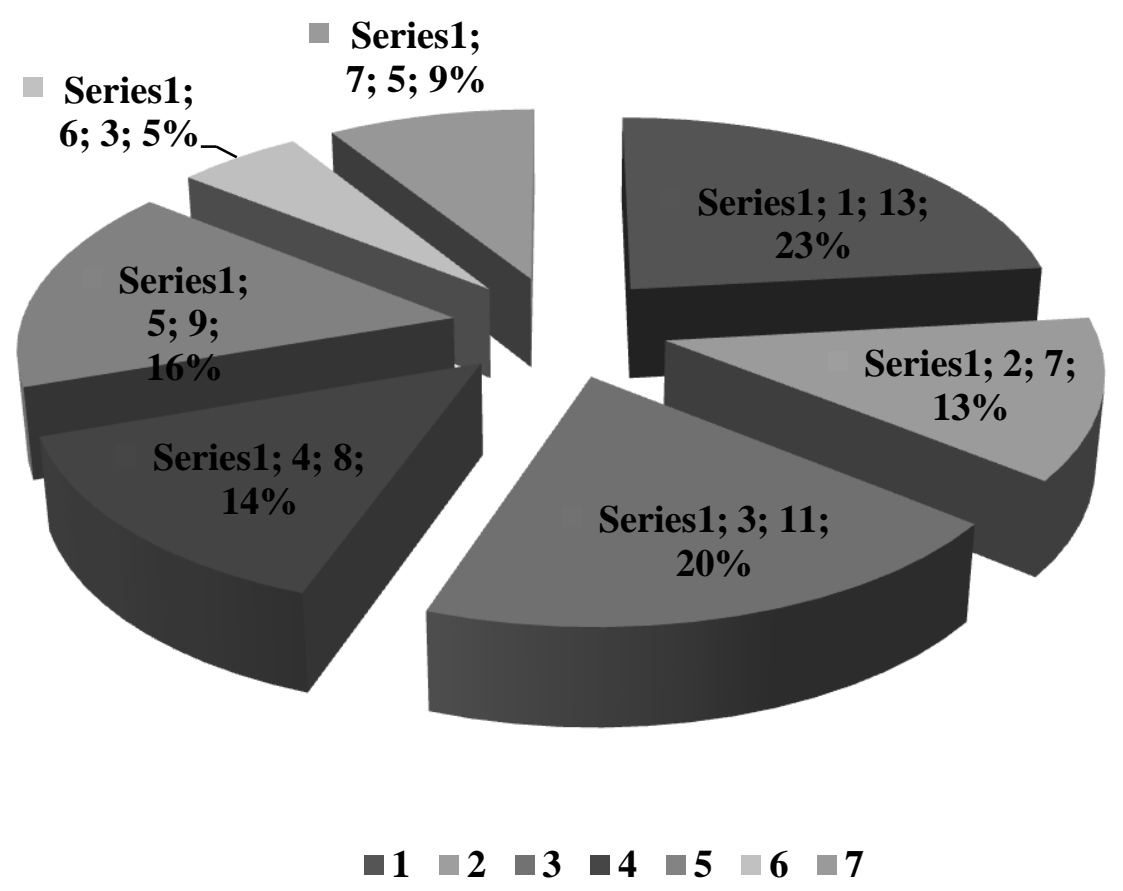

Figure 3. Ranking the importance of factor „bigger detachment and independence“

The highest relative share when ranking the importance of the factor ,better conditions for outdoor games and raising children" has been achieved by those ranking it first $-25 \%$. Not small is the share of those that have defined it as the least important - 13\% (Figure 4).

The weighed average rank of this factor is 3,4 . 


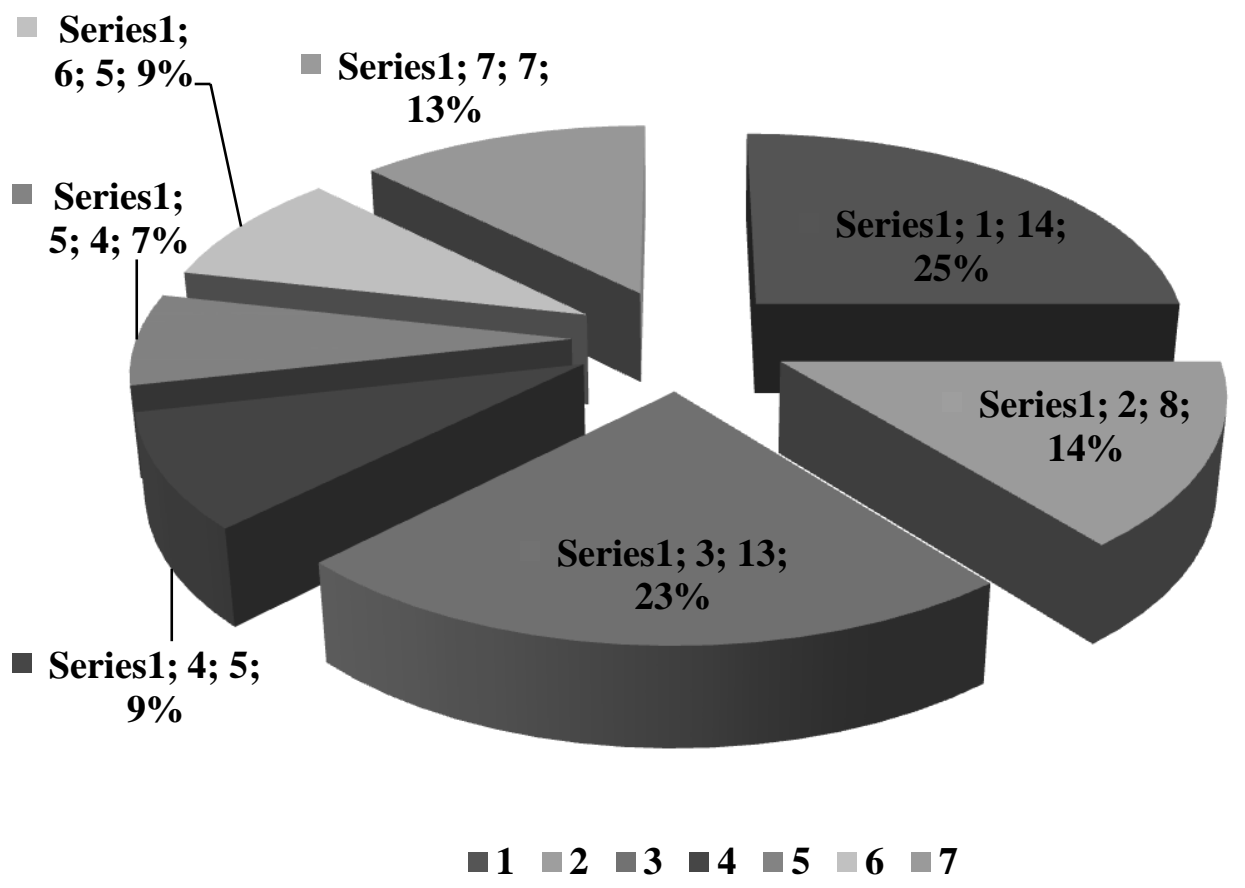

Figure 4. Ranking the importance of the factor „,better conditions for outdoor games and raising children“

„Feeling of belonging to a certain community“ is ranked first from only $9 \%$ of the interviewed. The smallest is the share of those that had ranked it second $-4 \%$. The majority

\section{Series1; 7; 7;}

$13 \%$

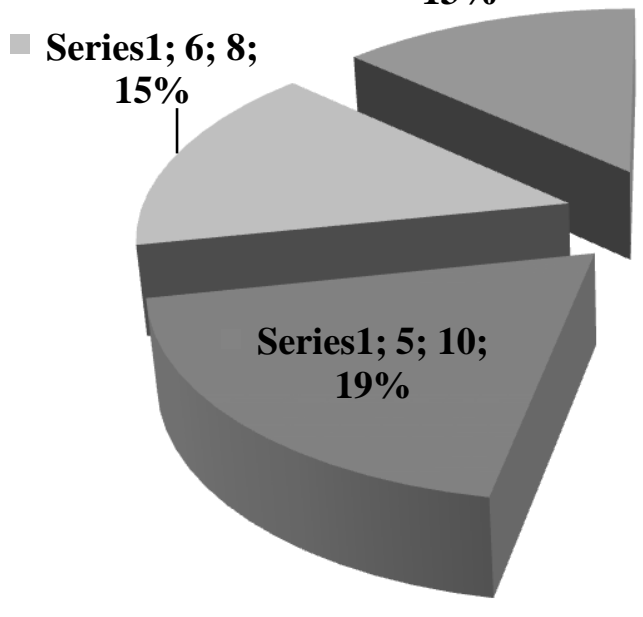

of the interviewed (25\%) has placed this factor on the fourth pace by importance (Figure 5).

The weighed average rank is 4,4 .

\section{- Series1; 1; 5;}

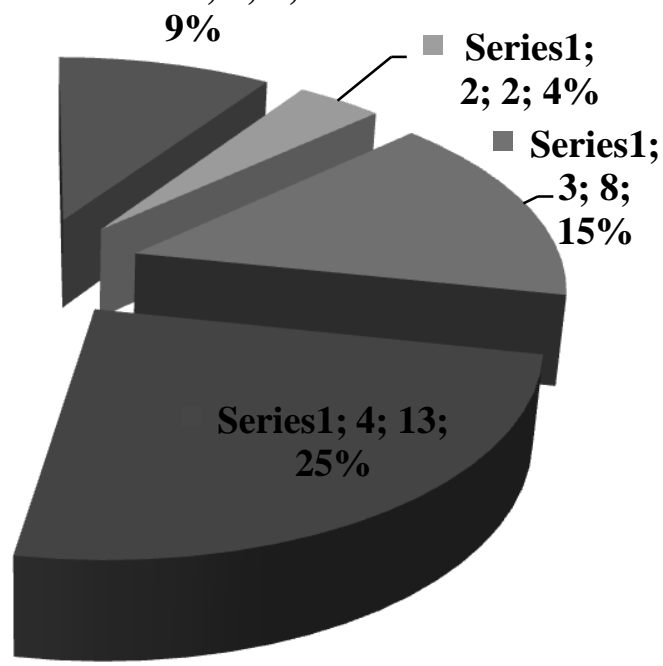

$\because 1 \backsim 2 \backsim 3 \square 4 \square 5 \square 6 \square 7$

Figure 5. Ranking the importance of the factor „Feeling of belonging to a certain community”

One fourth of the interviewed place the factor „,better preservation of existing Bulgarian cultural traditions, occupations and crafts" on the first place in importance. Slightly big is the percetange of those that have ranked this factor on the last place in importance - 19 (Figure 6) 3,7 is the value of the weighted average rank for this factor.
As you can see by the weighted average ranks, the highest rank is given to the factor ,more tranquility and lack of everyday stress", and the least importance for the interviewed has ,the feeling of belonging to a certain community". 


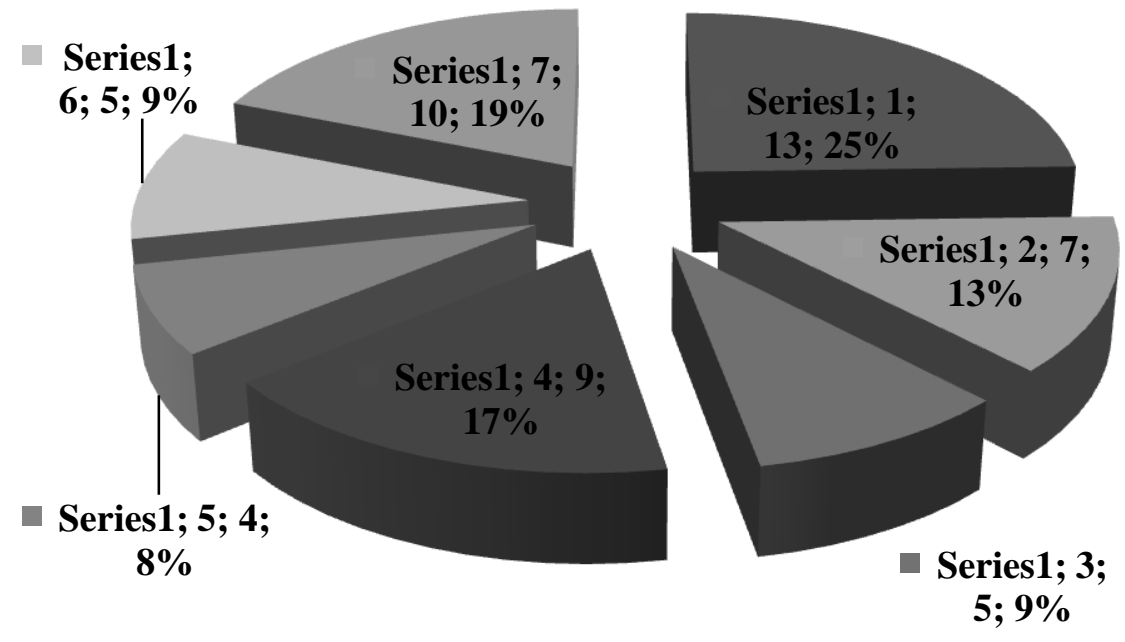

$\square 1 \square 2 \square 3 \square 4 \square 5 \square 6 \square 7$

Figure 6. Ranking the importance of the factor „,better preservation of existing Bulgarian cultural traditions, occupations and crafts"

When given a chance to assess the role of certain factors for the future development of small populated areas, the interviewed point out that the state has the decisive role; the European finds, local administration and local educational facilities - has significant role; local initiative groups (LIG), cooperations, private business and civil society - partial. Non-governmental organizations have predominantly insignificant role (Figure 7).

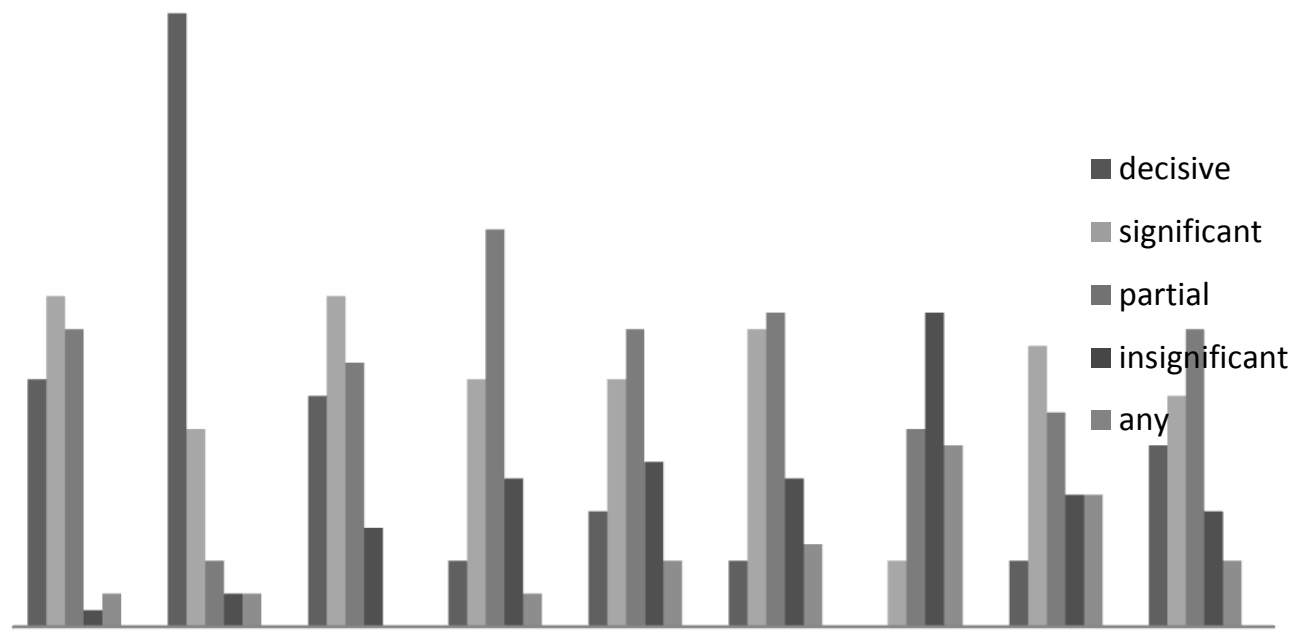

Figure 7. Assessment of Indicated Factors for the Future Development of Populated Areas

We can derive the following conclusions from this research:

1. Rural areas have certain specific characteristics that make them attractive for big portions of the population. Municipalities of Galabovo and Radnevo are no exception.

2. Tranquility and lack of everyday stress, as well as healthier and environmentally- friendly lifestyle are the main characteristics that make the researched rural areas attractive.

3. A decisive role for the development of smaller populated areas is given to the state. The role of European funds, local administration and local educational institutions is considerable. 
4. LIG, private business, cooperations and civil society have partial importance for the development of the researched rural areas.

\section{REFERENCES}

1. European Commission. Agriculture and development of Rural areas Policies for Rural Development 2007-2013, (available at:

http://ec.europa.eu/agriculture/rurdev/index _bg.htm ).

2. Rural Poverty Report 2011. International Fund for Agricultural Development (IFAD).

3. European Commission. Agriculture and Rural Development. Development of Rural Areas for the period 2014-2020 г., (available http://ec.europa.eu/agriculture/ruraldevelopment-2014-2020/index_bg.htm ).

4. Thematic Working Group 1: Targeting territorial specificities and needs in Rural Development Programmes Approaches to the definition of Rural Areas in 2007-2013 RDPs, (available at:

http://enrd.ec.europa.eu/enrdstatic/fms/pdf/24CFEFB0-BBCB-884C064B-FE2D76DDEB27.pdf).

5. Yanakieva Iv., Typology of.Rural Regions in Bulgaria. Economic Thought, 1: 22-41, 2007.

6. National Statistical Institute Data Territorial Statistical Office - Stara Zagora, 2015. 